\title{
Submonthly Convective Variability over South America and the South Atlantic Convergence Zone
}

\author{
BRANT LIEBMANN \\ Climate Diagnostics Center, University of Colorado, Boulder, Colorado \\ GEORGE N. KILADIS \\ Aeronomy Laboratory, National Oceanic and Atmospheric Administration, Boulder, Colorado \\ José A. MAREngo \\ Center for Weather Forecasts and Climate Studies, National Institute for Space Studies, Cachoeira Paulista, Brazil \\ TÉRCIO AMBrizZI \\ Department of Atmospheric Sciences, University of São Paulo, Sao Paulo, Brazil \\ JOHN D. GLICK \\ Climate Diagnostics Center, University of Colorado, Boulder, Colorado
}

(Manuscript received 14 March 1998, in final form 22 June 1998)

\begin{abstract}
Relationships between deep convection over South America and the atmospheric circulation are examined, with emphasis on submonthly variations of the South Atlantic convergence zone (SACZ) during austral summer. Outgoing longwave radiation (OLR) is used as a proxy for convection, while the associated circulation patterns are depicted by the National Centers for Environmental Prediction Reanalysis.

Over South America and the adjacent oceans, OLR fluctuations with periods less than 90 days show maximum variance in the SACZ and over central South America during December-February. There is a local minimum in variance over the southern Amazon Basin, where mean convection is at a maximum. OLR spectra display several statistically relevant peaks corresponding to periods of less than 30 days over tropical South America, with the relative proportion of higher-frequency power increasing as the base grid point is moved to the southeast within the SACZ.

Correlations between submonthly (2-30-day) OLR in the vicinity of the SACZ and 200-mb streamfunction reveal the preferred path of Rossby wave energy impinging on the SACZ from the midlatitudes of the Southern Hemisphere. Episodes of enhanced convection within the SACZ, indicated by negative OLR anomalies, occur at the leading edge of upper-level troughs propagating into the region. The corresponding pattern at $850 \mathrm{mb}$ reveals that the disturbances are nearly equivalent barotropic west of South America but tilt westward with height in the region of the SACZ. Negative low-level temperature anomalies lie to the southwest of the convection. The results are consistent with baroclinic development along an associated cold front.

Convection over the southwestern Amazon Basin on submonthly timescales is seen to progress into the region from the south. Upper-level anomalies, which at times may play a role in the initiation of the convection, move eastward and rapidly become decoupled from the convection. Low-level cold air along the eastern flank of the Andes appears linked to the convection as it moves northward. In contrast, convection over the southeastern Amazon is accompanied by disturbances moving into the area from the Atlantic, but there is little sign of a low-level temperature anomaly. In this case convection seems to result in cross-equatorial outflow into the North Atlantic, rather than be the result of forcing from the extratropics.

The authors speculate that the relatively stable position of the SACZ is associated with a Rossby wave guide, which ultimately is related to the large-scale circulation driven by sources and sinks of diabatic heating. It also appears that the SACZ forms when the northwesterly flow associated with a low-level trough is able to tap moisture from the Amazon.
\end{abstract}

Corresponding author address: Brant Liebmann, NOAA-CIRES Climate Diagnostics Center, University of Colorado, Campus Box 216 , Boulder, CO 80309-0216.

E-mail: bl@cdc.noaa.gov 


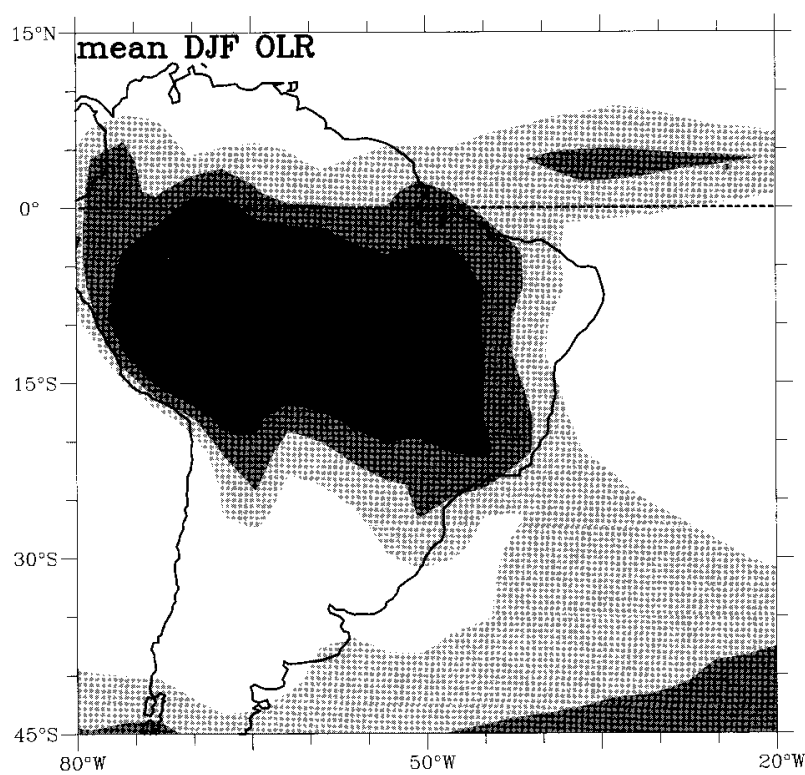

FIG. 1. Average OLR for months of DJF, beginning Jan 1979, and ending Feb 1996. Shading begins at $245 \mathrm{~W} \mathrm{~m}^{-2}$, with an interval of $15 \mathrm{~W} \mathrm{~m}^{-2}$. Darkest shade begins at $200 \mathrm{~W} \mathrm{~m}^{-2}$.

\section{Introduction}

The South Atlantic Convergence Zone (SACZ) is the dominant summertime cloudiness feature of subtropical South America and the western South Atlantic Ocean. It is readily seen on maps of climatological summertime outgoing longwave radiation (OLR; see Fig. 1), high clouds (e.g., Kodama 1993), and precipitation (e.g., Nogués-Paegle and Mo 1997). Normally, the SACZ is a cloud band that appears to either emanate from or merge with the intense convection of the Amazon Basin, extending from tropical South America southeastward into the South Atlantic Ocean.

The SACZ varies on many timescales, although it seldom persists for more than 10 days at a time (e.g., Figueroa et al. 1995). Casarin and Kousky (1986) used 15-day averages of OLR to define episodes of drought in southern Brazil and found the composite anomaly associated with these extremes to bear the signature of a weakened SACZ. Using rotated empirical orthogonal functions, Nogués-Paegle and Mo (1997) also found evidence of large intraseasonal variations in the SACZ. They noted a half-period of around 10 days for variations within the cloud band.

Kodama $(1992,1993)$ examined the common features between the SACZ, the South Pacific convergence zone (SPCZ), and the Baiu frontal zone over the south Asian monsoon region. He found that all of these convergence zones extend poleward and eastward from localized monsoon convection anchored near the equator, and form along the subtropical jets associated with the eastern part of the troughs that penetrate into the subtropics. At the surface they generally are located poleward and westward of subtropical highs, and are usually best de- veloped during the summer season. He showed that the moisture supply to the tropical portion of the convergence zones originates in the monsoon part, while moisture within the subtropical part is advected poleward into the region by the subtropical high. Kodama also noted an approximate 10-day half-period of convection in the convergence zones.

The results of Kodama suggest that the mean position of the SACZ may somehow be attributable to the deep convection of the Amazon Basin. Figueroa et al. (1995) were able to reproduce low-level convergence in the vicinity of the SACZ in an eta-coordinate model using a heat source intended to mimic deep Amazonian convection, provided they used a realistic orography and background wind field. They also determined that a successful simulation was dependent on a heat source that varied diurnally. They found the SACZ to form 12-18 h after a peak in Amazon convection, suggesting that short-term variations in the cloud band may be influenced by deep convection in the Amazon. On the other hand, Lenters and Cook (1995) found a realistic SACZ in a general circulation model (GCM) that did not include diurnal variability. They also pointed out the importance of transient moisture flux from the Amazon, as related to extratropical cyclones and fronts, in maintaining the model SACZ.

Casarin and Kousky (1986), Kiladis and Weickmann (1992a), Nogués-Paegle and Mo (1997), and Lenters and Cook (1998) all suggest a link between variations of the SACZ and the Madden-Julian oscillation (MJO; Madden and Julian 1994) on the 30-60-day timescale. Several of these studies show the SACZ to vary as part of a dipole, with an enhanced SACZ being associated with anomalously high OLR (implying low rainfall) centered over Uruguay and extending into Argentina. This dipole, whose centers are elongated from northwest to southeast, suggests forcing by a Rossby wave train propagating toward the equator (e.g., Kiladis and Weickmann 1992b, 1997), with negative OLR anomalies occurring in the region of expected uplift ahead of an upper-level trough, and positive OLR anomalies in the subsidence region ahead of an upper ridge. Grimm and Silva Dias (1995) found, using a barotropic model with a January basic state, that divergence in the region of the SPCZ exerts an influence in the region of the SACZ through Rossby wave propagation. This wave activity appears to propagate along a Rossby wave guide, at first poleward until it reaches its turning latitude in the Southern Hemisphere midlatitudes, then northward in the vicinity of South America (e.g., Hoskins and Ambrizzi 1993). At higher frequencies, Kiladis and Weickmann (1992a, 1997) found evidence that SACZ variations are forced by wave activity originating in the extratropics on submonthly (6-30 day) timescales.

Although the SACZ shows a preferred geographical location, higher-frequency teleconnection patterns are not always rigidly fixed in space (e.g., Blackmon et al. 1984). Thus it seems likely that the large-scale basic 
flow, maintained in part by Amazon convection, plays a role in positioning the SACZ (e.g., Figueroa et al. 1995).

The main purpose of the present study is to document and understand the transient large-scale circulation that leads to variability of SACZ convection during December through February on timescales of less than a month, and to compare that variability with the circulation leading to tropical convection in other parts of South America. Our hypothesis is that while the mean position of the SACZ may be influenced by the location of Amazon convection, the Andes, and the Atlantic subtropical high, the day-to-day variations are driven by wave activity originating in the extratropical westerlies of the Southern Hemisphere.

\section{Data and methodology}

For this study, National Centers for Environmental Prediction reanalysis data are used to represent the large-scale circulation and OLR is utilized as a proxy for deep convection. Both of these datasets are on a $2.5^{\circ}$ grid. The original twice-daily OLR data have been interpolated in space and time to yield a global set with no missing data during the study period (Liebmann and Smith 1996). The reanalysis data provide a consistently derived set that is not subject to operational constraints or changes in the assimilation system (Kalnay et al. 1996). Four times daily grids were averaged to produce daily averages used in this study. The 17-season study period spans December-February (DJF) 1979/80 to 1995/96.

Rainfall is estimated from a set of daily rainfall accumulations scattered throughout the Amazon Basin and southeast Brazil acquired from the archives of the Brazilian National Agency for Electric Energy. We choose to utilize a subset of 781 of these records that has data for at least 4 yr from 1979 to 1996 and has less than $33 \%$ missing or determined as likely erroneous. An average of 14-yr data are available at each station, and, of these available records, $7.5 \%$ are missing. All available data are averaged onto a $2.5^{\circ}$ lat-long grid.

A linear regression technique, described in detail by Kiladis and Weickmann (1992a), is used to examine the horizontal and vertical structure of the typical modes of circulation associated with deep convection over the eastern Pacific during the DJF season. Temporal filtering of the data is accomplished by using a Lanczos digital filter with 121 daily weights, giving very sharp response cutoffs with negligible Gibbs oscillation (Duchon 1979).

The predictor OLR dataset was high-pass filtered to retain fluctuations on the less than 30-day timescale. This effectively results in a 2-30-day bandpass filtering, although the cutoff at 2 days is not sharp due to the daily averaging used. This filtering removes the seasonal cycle and excludes variability due to the MJO. The band is still very broad and contains at least two-thirds of the intraseasonal variance of OLR over the study region once the seasonal and diurnal cycles are removed (see Fig. 3c).

To establish the relationship between deep convection and circulation, filtered OLR in a selected $10^{\circ}$ square base region is regressed against the raw zonal and meridional components of the wind, OLR, temperature, and streamfunction at each global grid point. This procedure yields a separate regression equation between OLR in the base region and the predictand at each global grid point. The linear dependence can then be mapped by applying the regression equation for each grid point using an arbitrary deviation in OLR at the base region as the independent variable. Lagged regressions can be used to examine the evolution of the relationships over time.

Negative anomalies in OLR generally occur during periods of high-level cloudiness, and the reconstructed circulations are meant to represent those associated with deep convection at the base region. In the studies of Kiladis and Weickmann (1992b, 1997), a large region of OLR less than $220 \mathrm{~W} \mathrm{~m}^{-2}$ was typically observed within the SACZ during periods of enhanced cloud band activity. This corresponds to an OLR anomaly of more than $-30 \mathrm{~W} \mathrm{~m}^{-2}$ below the DJF long-term mean at that location. In the present study, we scale the regressions to a value of $-30 \mathrm{~W} \mathrm{~m}^{-2}$ to produce realistic amplitudes of the circulations associated with precipitation events within the SACZ.

The correlation coefficient enables the statistical significance of the local linear relationship between OLR in the base region and the dependent variable at any given grid point to be assessed. All of the maps shown here are field significant (Livezey and Chen 1983) at greater than the $95 \%$ level for a global domain. Further discussion of statistical significance can be found in Kiladis and Weickmann (1992a, 1997).

\section{Results}

\section{a. Mean and variance}

The December-February average of OLR is shown in Fig. 1. While the deep convection of the southern Amazon Basin is the dominant feature of this domain, there is evidence of a southeastward extension of low values of OLR into the Atlantic, which denotes the mean position of the SACZ. Convection here, however, is implied to be weaker than in the Amazon. The OLR pattern is consistent with the mean precipitation pattern from microwave sounding unit data shown by Nogués-Paegle and Mo (1997). The zonally oriented Atlantic ITCZ near $4^{\circ} \mathrm{N}$ is also clearly shown, although it too shows weaker convection than in the Amazon.

Power spectra of OLR in the SACZ and over the Amazon Basin are computed for a 210-day series beginning 1 October of each year using high-pass filtered data with a cutoff of 90 days, shown in Fig. 2. A 60day taper was applied to each end of the series, leaving 


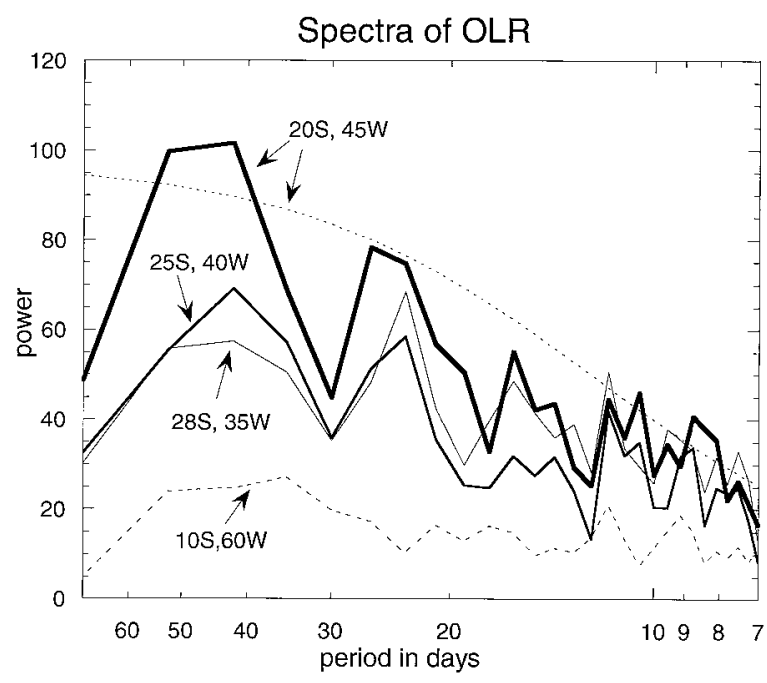

FIG. 2. Average power spectra of OLR for points at locations shown in figure. Spectra for 210-day series beginning 1 Oct are computed and averaged over all years. First and last 60 days of each series are tapered. Also shown is the red noise spectrum for the uppermost curve, computed from the lag-one autocorrelation.

the December-February data unaffected. At each grid point of interest, spectra are calculated for individual years and these are then averaged.

The three solid curves in Fig. 2 are spectra for grid points in the SACZ. The low-frequency end of the spectrum is not well resolved, but these spectra all show a peak near 50 days (corresponding to the MJO), and peaks near 27, 16, 10, and 8 days. The upper dashed curve shows the red spectrum based on the one-lag autocorrelation for the point whose spectrum is shown in the uppermost curve. The close correspondence between the spectral peaks at different locations, as well as their amplitude compared to a red-noise spectrum, suggests that the peaks are robust. The relative amplitude of the higher-frequency peaks becomes larger as the point is moved to the southeast. For contrast, the lowest curve is the average spectrum for a point over the Amazon Basin $\left(10^{\circ} \mathrm{S}, 60^{\circ} \mathrm{W}\right)$. At this location the near-25- and near-16-day peaks are almost entirely absent, but the higher-frequency peaks are similar to those at the locations within the SACZ.

Figure $3 \mathrm{a}$ shows the variance of less than 90-day filtered data. The SACZ and a separate center over land near $25^{\circ} \mathrm{S}, 55^{\circ} \mathrm{W}$ dominate the variance field. These areas of maximum subseasonal variability lie on the poleward side of the regions of deepest convection shown in Fig. 1. In fact, there is a minimum in variance over

FIG. 3. Variance of OLR for (a) periods less than 90 days for DJF Shading begins at $800 \mathrm{~W}^{2} \mathrm{~m}^{-4}$ with an interval of $200 \mathrm{~W}^{2} \mathrm{~m}^{-4}$. (b) Interannual means for DJF averages. Shading begins at $25 \mathrm{~W}^{2} \mathrm{~m}^{-4}$ with an interval of $25 \mathrm{~W}^{2} \mathrm{~m}^{-4}$. (c) Ratio of 2-30-day to 30-90-day variances of OLR for DJF. Shading starts at 4 , with an interval of 4 .
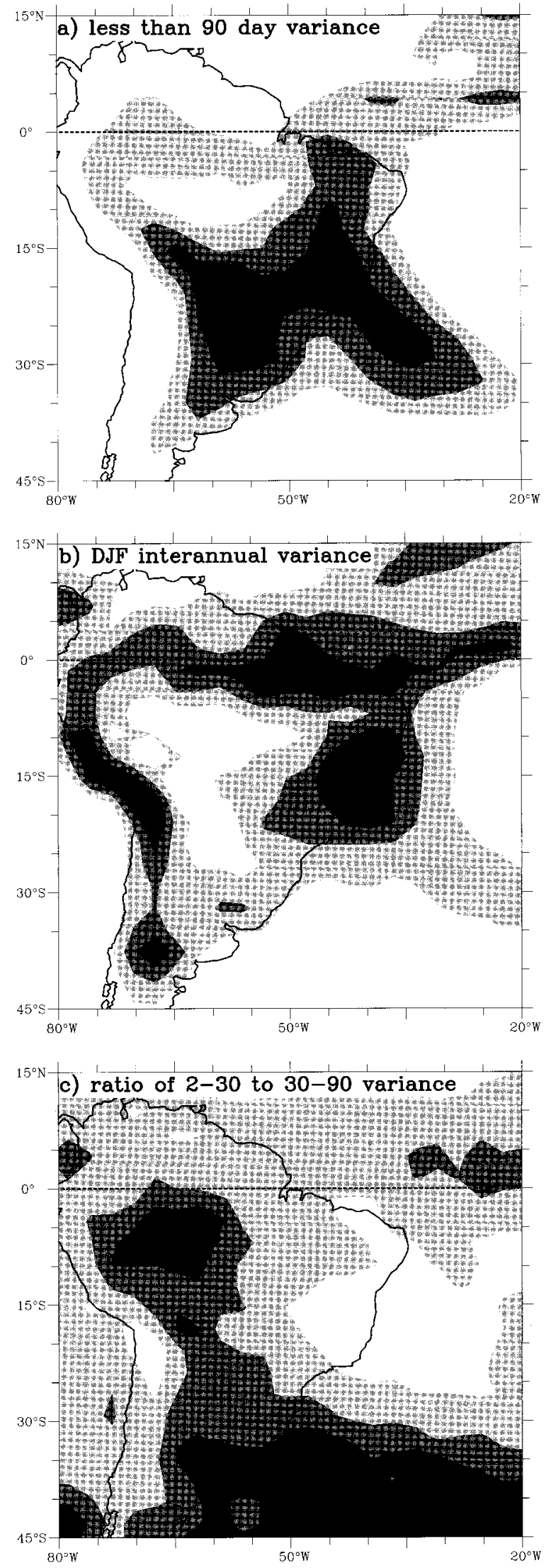
the southern Amazon Basin, where the mean OLR is lowest. The location of the variance maximum over Paraguay coincides with the region of most frequent mesoscale convective complexes (MCCs) during summer (Velasco and Fritsch 1987; Mohr and Zipser 1996). Moisture from the Amazon feeds these MCCs via a strong northerly low-level jet located east of the Andes (e.g., Virji 1981; Paegle 1987). This low-level jet was observed in the composites of vertically integrated meridional moisture flux by Nogués-Paegle and Mo (1997).

For comparison, interannual variance (from DJF averages) is shown in Fig. 3b. As with subseasonal variance, interannual variance is also a minimum over the southern Amazon. A minimum in interannual variance, however, extends into central South America, where less than 90-day variance is maximum (Fig. 3a). There are centers of maximum variance located over the Andes Altiplano at about $20^{\circ} \mathrm{S}$, near the mouth of the Amazon extending eastward and westward along the equator, and on the equatorward side of the SACZ.

Much of the interannual convective activity over the Altiplano is related to the Southern Oscillation, with reduced (increased) rainfall during warm (cold) events (Horel et al. 1989; Lenters and Cook 1998). On the other hand, a dry Altiplano appears to be associated with increased convective activity in the SACZ, and vice versa (Aceituno 1988; Rao and Hada 1990; Gan and Rao 1991; Lenters and Cook 1998). The maximum in variance over northern Brazil along the equator appears to be related to displacements of the Atlantic ITCZ (e.g., Hastenrath 1991).

Variance in the 2-30-day band (not shown) is qualitatively quite similar to the total subseasonal variance. The ratio of 2-30-day variance to that in the 30-90-day band (Fig. 3c), however, reveals the largest proportion to be over the Amazon, where total variance is a minimum, and south of about $30^{\circ} \mathrm{S}$. The SACZ is in a region of relatively low ratios, even though there is still more than three times as much variance in the 2-30- as in the 30-90-day band. This map is consistent with Fig. 2 , as both show an increase in the relative importance of higher-frequency fluctuations from northwest to southeast within the SACZ.

\section{b. Submonthly lead and lag relationships}

\section{1) $\mathrm{SACZ}$}

To examine circulation anomalies associated with submonthly variations in the SACZ, we regress 2-30day filtered OLR averaged over a $10^{\circ}$ box $\left(20^{\circ}-30^{\circ} \mathrm{S}\right.$, $40^{\circ}-30^{\circ} \mathrm{W}$ ) within the SACZ against various parameters on the global grid. This box is centered in the region of maximum 2-30-day OLR variance discussed in the previous section.

Figure 4 shows the evolution of 200-mb streamfunction from two days prior (day -2) to 2 days following $($ day +2$)$ the peak in SACZ convection, which by design
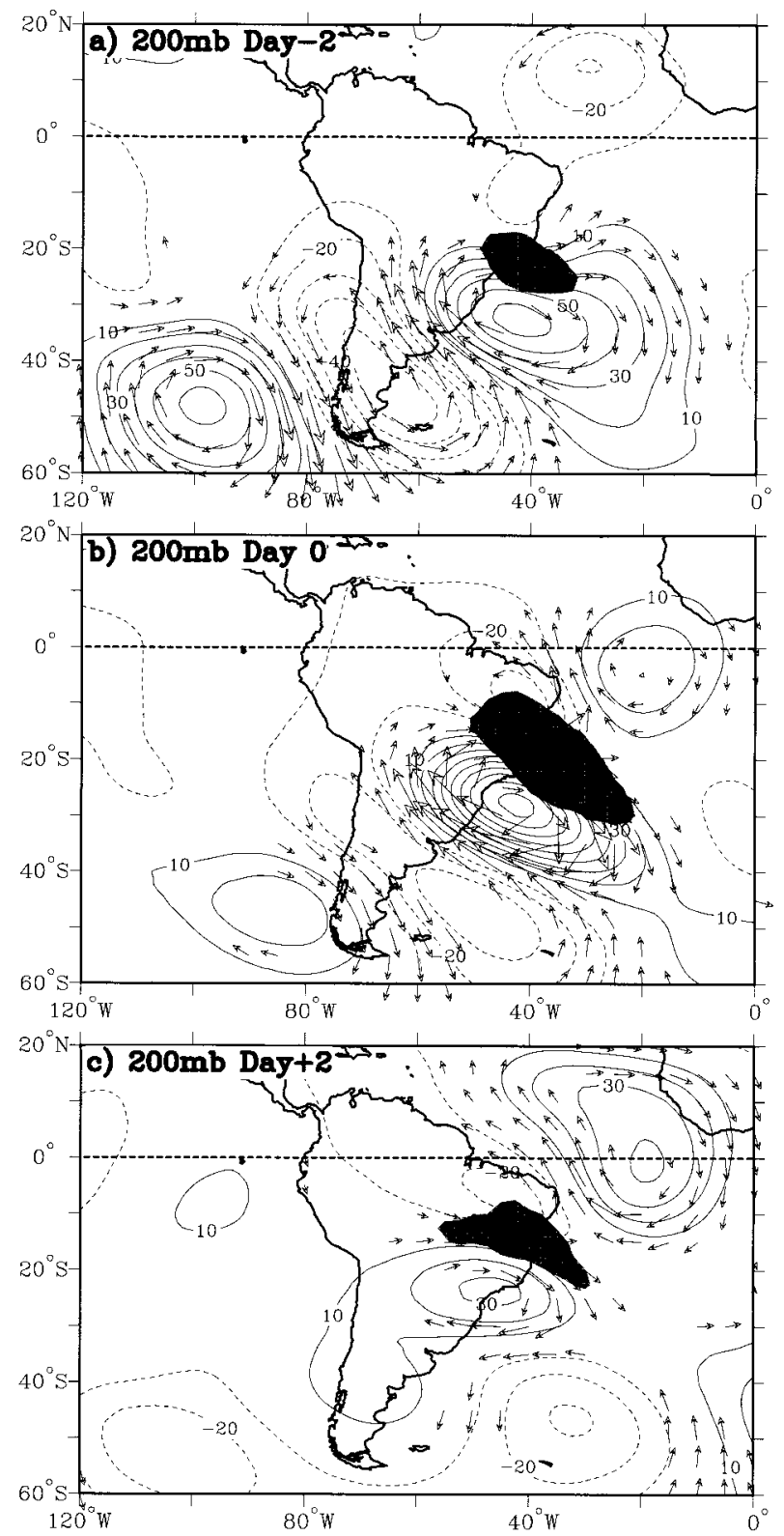

FIG. 4. 200-mb streamfunction, wind, and OLR perturbations associated with a $-30 \mathrm{~W} \mathrm{~m}^{-2}$ deviation in 2-30-day filtered OLR in the region $20^{\circ}-30^{\circ} \mathrm{S}, 40^{\circ}-30^{\circ} \mathrm{W}$ during DJF. (a) Day -2 , (b) day 0 , (c) day +2 . Contour interval is $10 \times 10^{5} \mathrm{~m}^{2} \mathrm{~s}^{-1}$, with negative contours dashed and the zero contour omitted. Shading denotes OLR anomalies less than $-10 \mathrm{~W} \mathrm{~m}^{-2}$. Locally statistically significant wind vectors are shown, with the largest vectors representing a wind speed of about $10 \mathrm{~m} \mathrm{~s}^{-1}$. Box in (b) outlines outermost grid points used in average.

will occur in the base region at day 0 . Also plotted are locally statistically significant wind vectors. "Significance" means that one rejects the null hypothesis for either the zonal or meridional component of wind at the a posteriori $95 \%$ level, using the Student's t-test. In that case, both components of the vector are plotted.

On day -2 (Fig. 4a), a cyclonic perturbation is lo- 


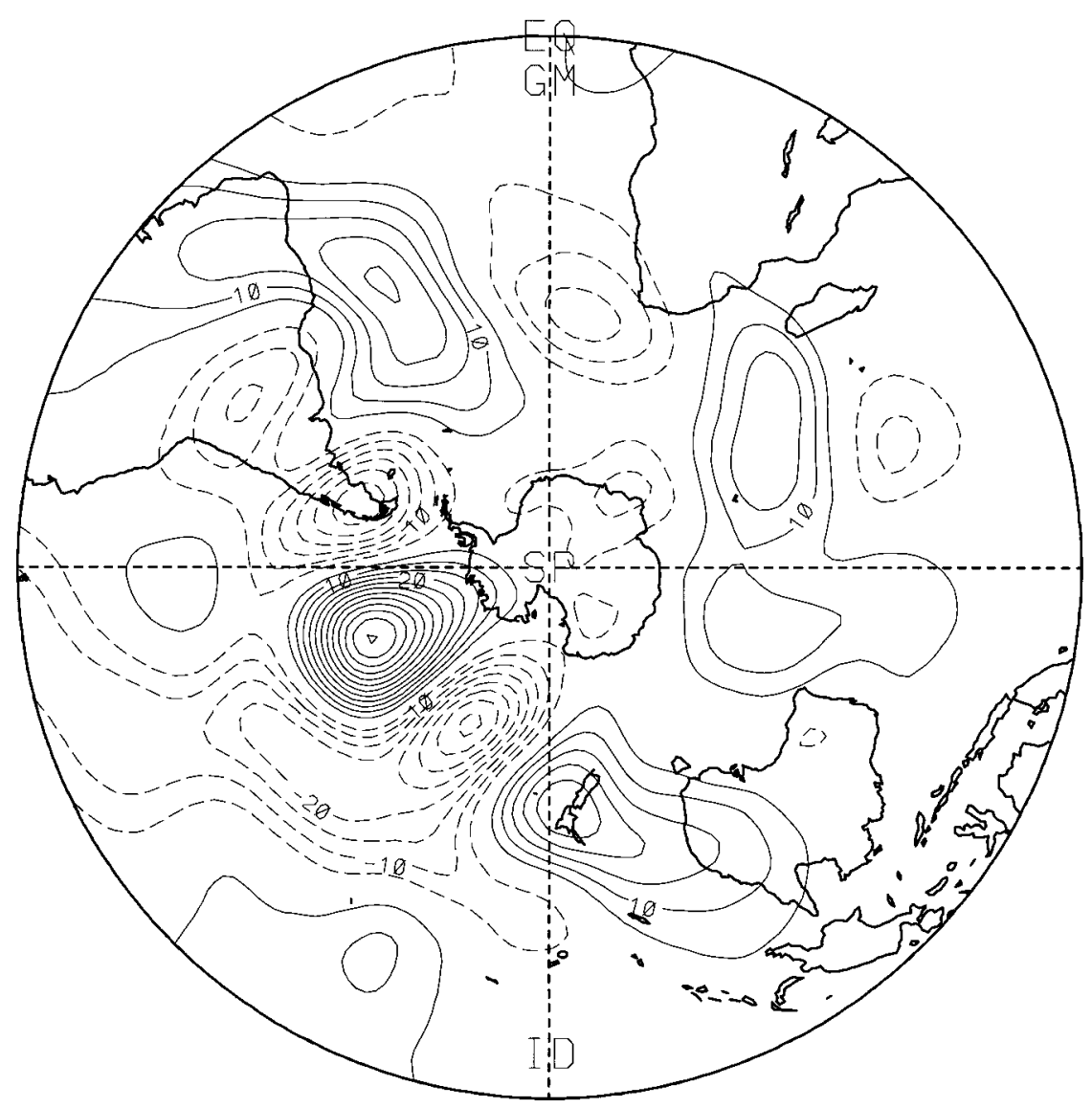

FIG. 5. As in Fig. 4 except that streamfunction leads OLR by 4 days, and contours are at intervals of $5 \times 10^{5} \mathrm{~m}^{2} \mathrm{~s}^{-1}$.

cated south of low OLR over the east coast of Brazil and is part of a northwest-southeast-oriented wave train extending into the region from the South Pacific. As the trough amplifies, the region of low OLR expands both equatorward and southeastward into the characteristic signal of SACZ cloudiness on day 0 (Fig. 4b). By day +2 (Fig. 4c) the upper-level trough has weakened, although energy dispersing through the wave train is evident, which ultimately crosses the equator over the Atlantic. The trough associated with the OLR signal is quasi-stationary throughout the sequence, showing only a slight northward movement, as opposed to the southern part of the wave train in which features are progressing more rapidly eastward.

The evolution in Fig. 4 is consistent with previous studies of circulation versus OLR on subseasonal timescales in upper-level westerlies, or where westerlies lie close to regions of tropical convection (e.g., Liebmann and Hartmann 1984; Kiladis and Weickmann 1992b, 1997). In these areas Rossby waves originating in the extratropics can propagate to low latitudes and interact with tropical convection such that convection appears to be forced in the region of uplift ahead of an upper- level trough, due to the advection of potential vorticity (see Kiladis 1998).

Figure 5 shows a polar stereographic projection of the Southern Hemisphere (SH) 200-mb streamfunction on day -4 of the sequence corresponding to Fig. 4 (note the contour interval is half that of Fig. 4). The wave train of perturbations leading to the SACZ cloudiness signal follows a nearly great circle route from a region near New Zealand, across the high latitudes of the South Pacific, and then equatorward over South America. The signal is typical of the zonal wavenumber-5 perturbation patterns that occur frequently within the $\mathrm{SH}$ westerlies, especially during southern summer (Kidson 1991; Kidson and Sinclair 1995). The path over the Pacific-American sectors is a preferred route of energy dispersion isolated by Ambrizzi and Hoskins (1997), who inferred the existence of a Rossby wave guide along the South Pacific jet and into the subtropics of the South Atlantic during southern summer using idealized baroclinic model experiments. Thus the initial wave energy responsible for forcing SACZ perturbations originates well upstream over the westerly storm track of the South Pacific Ocean. A series of maps highlighting the regression between 

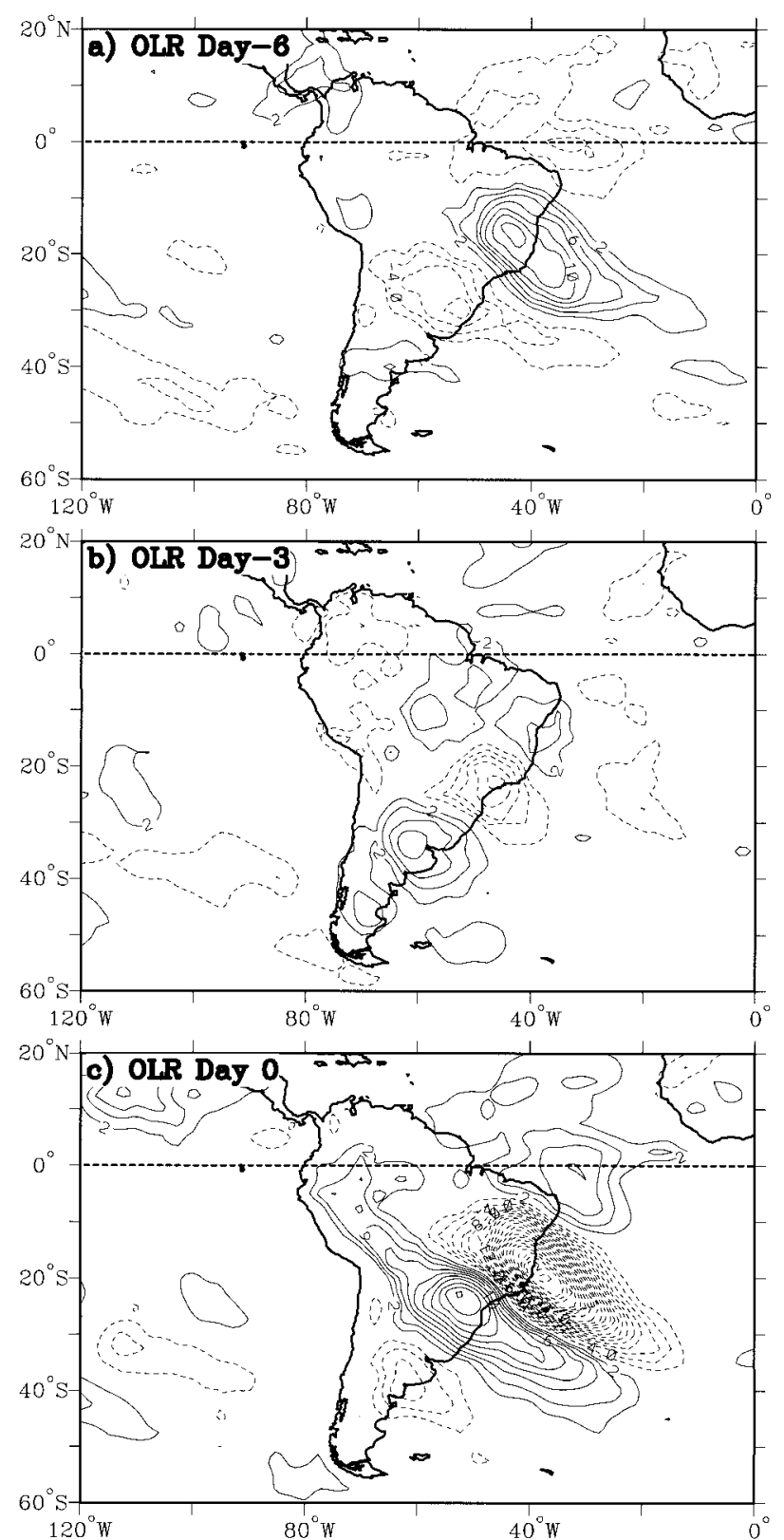

FIG. 6. As in Fig. 4 except OLR is regressed against itself for (a) field leading base by 6 days, (b) field leading base by 3 days, and (c) field simultaneous with base. Contours are at intervals of $2 \mathrm{~W}$ $\mathrm{m}^{-2}$, with zero contour omitted.

OLR and itself is shown in Fig. 6. By extending this sequence back to day -6 (Fig. 6a), the equatorward movement of the OLR signal is seen to be embedded in a tilted wave train of alternating OLR perturbations, with negative (positive) OLR ahead of upper troughs (ridges) in Fig. 4. The simultaneous regression (Fig. 6c) is reminiscent of the fifth rotated empirical orthogonal function pattern found by Nogués-Paegle and Mo (1997), with enhanced convection in the SACZ and suppressed convection to the southwest. The pattern on day
-6 is similar to that at day 0 except with opposite sign, implying an average 13-day period of the SACZ convection. This is confirmed by the full sequence of lag maps of streamfunction and OLR (not shown), in which the day -6 and day +6 patterns are quite similar.

There is little evidence in Fig. 6 that anomalies in Amazonian convection are related to submonthly SACZ anomalies. Instead there is a weak simultaneous out-ofphase relationship between OLR in the SACZ and the Atlantic ITCZ in Fig. 6c. In fact, the sequence from day -6 to day 0 gives the impression that, over time, the OLR perturbations are progressing toward and crossing the equator along the east coast of South America. This is also seen at positive lags, such that equatorial convection is enhanced once again at day +6 (not shown). Thus the primary association with OLR signals within the SACZ on submonthly timescales appears to be with disturbances originating in the extratropics, not over Amazonia.

The vertical structure of the disturbances associated with SACZ convection can be seen by comparing the 850 -mb streamfunction pattern (Fig. 7) to that at 200 $\mathrm{mb}$. Comparing these figures, there is a notable poleward and westward tilt with height of the features between 850 and $200 \mathrm{mb}$, except for the features to the west over the open ocean, which are nearly equivalent barotropic, as is typically observed both the Southern (e.g., Kidson 1991) and Northern (e.g., Hsu 1987) Hemispheres. The vertical tilt of the cyclone-anticyclonic couplet along the southeast coast is indicative of a developing baroclinic wave. While the OLR signals tend to be in quadrature with the upper-level vorticity pattern, at day 0 the deepest convection is close to the center of the lowlevel cyclonic circulation. In addition, a comparison between Figs. $7 \mathrm{~b}$ and $6 \mathrm{c}$ shows that at $850 \mathrm{mb}$ on day 0 the deepest convection lies within the low-level northwesterly flow, where maximum moisture transport from the Amazon would be expected.

Figure 8 shows the corresponding $1000-\mathrm{mb}$ geopotential anomalies, qualitatively similar to sea level pressure anomalies, although here we show a sequence starting on day -4 to highlight the evolution of surface pressure leading up the SACZ activity. When geopotential leads the OLR base point by 4 days (Fig. 8a), a surface anticyclone has already built equatorward to the east of the Andes, with positive pressure perturbations extending well into the Tropics. These equatorward "pressure surges" are a common occurrence along the eastern sides of topography (e.g., Garreaud and Wallace 1998). By day -2 (Fig. 8b), the surface cyclone in the Pacific is slightly weakened, while the high pressure surge has pushed farther toward the equator. The surge is associated with low-level southerly flow along the mountains, most evident at $850 \mathrm{mb}$ (refer to Fig. 7a) where it even crosses the equator. A weak low over the South Atlantic has developed and retrograded westward toward the coast to the mean position of the SACZ, consistent with the development of the upper-level 

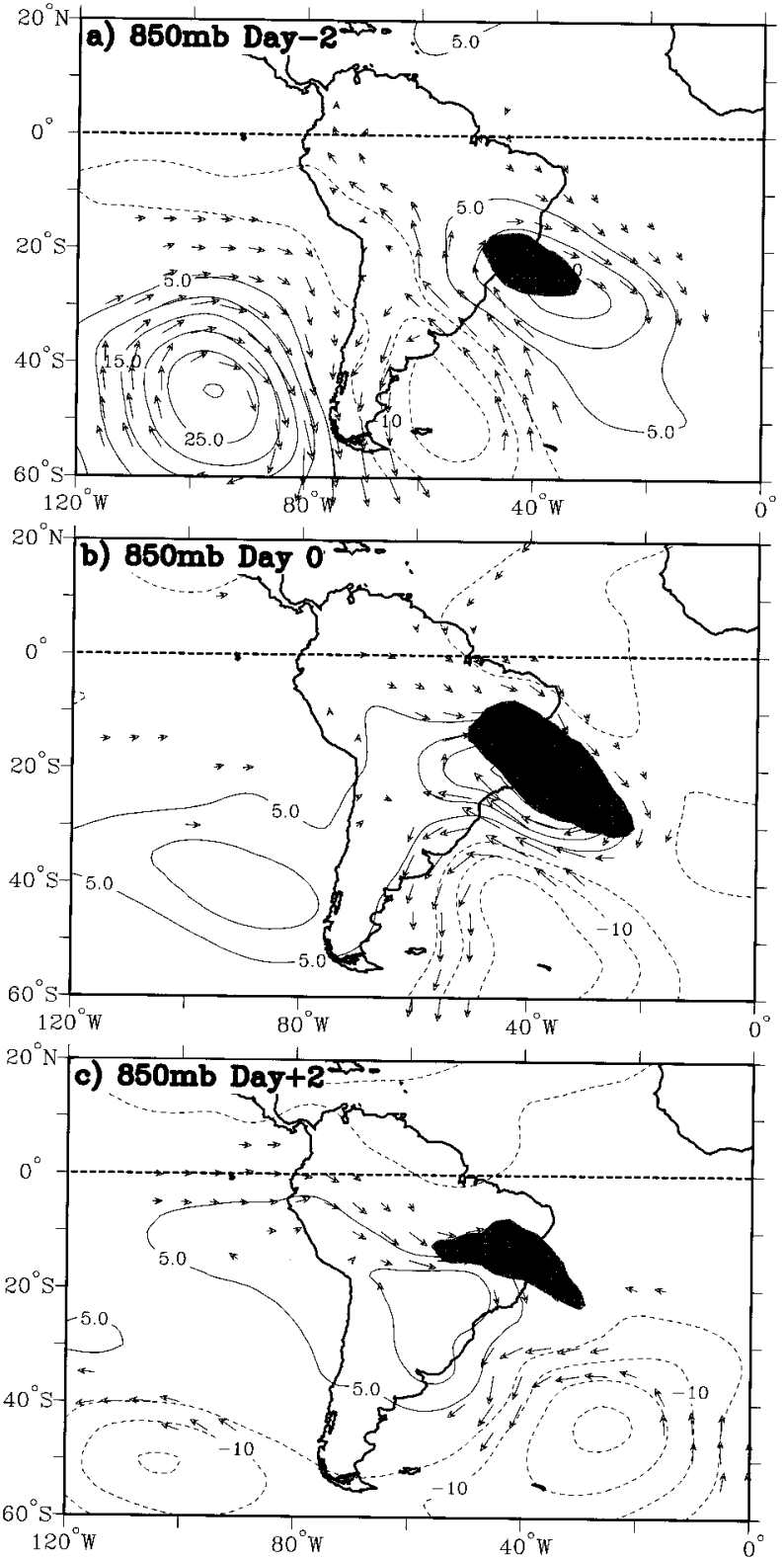

FIG. 7. As in Fig. 4 except field is 850 -mb streamfunction and contours are at intervals of $5 \times 10^{5} \mathrm{~m}^{2} \mathrm{~s}^{-1}$.

trough to its southwest. By day 0 (Fig. 8c) the core of the southern anticyclone has progressed eastward into the South Atlantic and the low centered near the negative OLR anomaly in the SACZ has developed further. The convective signal again lies within and slightly equatorward of a surface low pressure zone with a welldeveloped cyclonic circulation. Analyzed surface convergence (not shown) lines up well with OLR.

The sequence of surface temperature anomalies associated with the development of SACZ convection is shown in Fig. 9. At day -2, Patagonia is anomalously warm (Fig. 9a), while cold temperatures lie southwest of the growing OLR anomaly. By day 0 (Fig. 9b), the
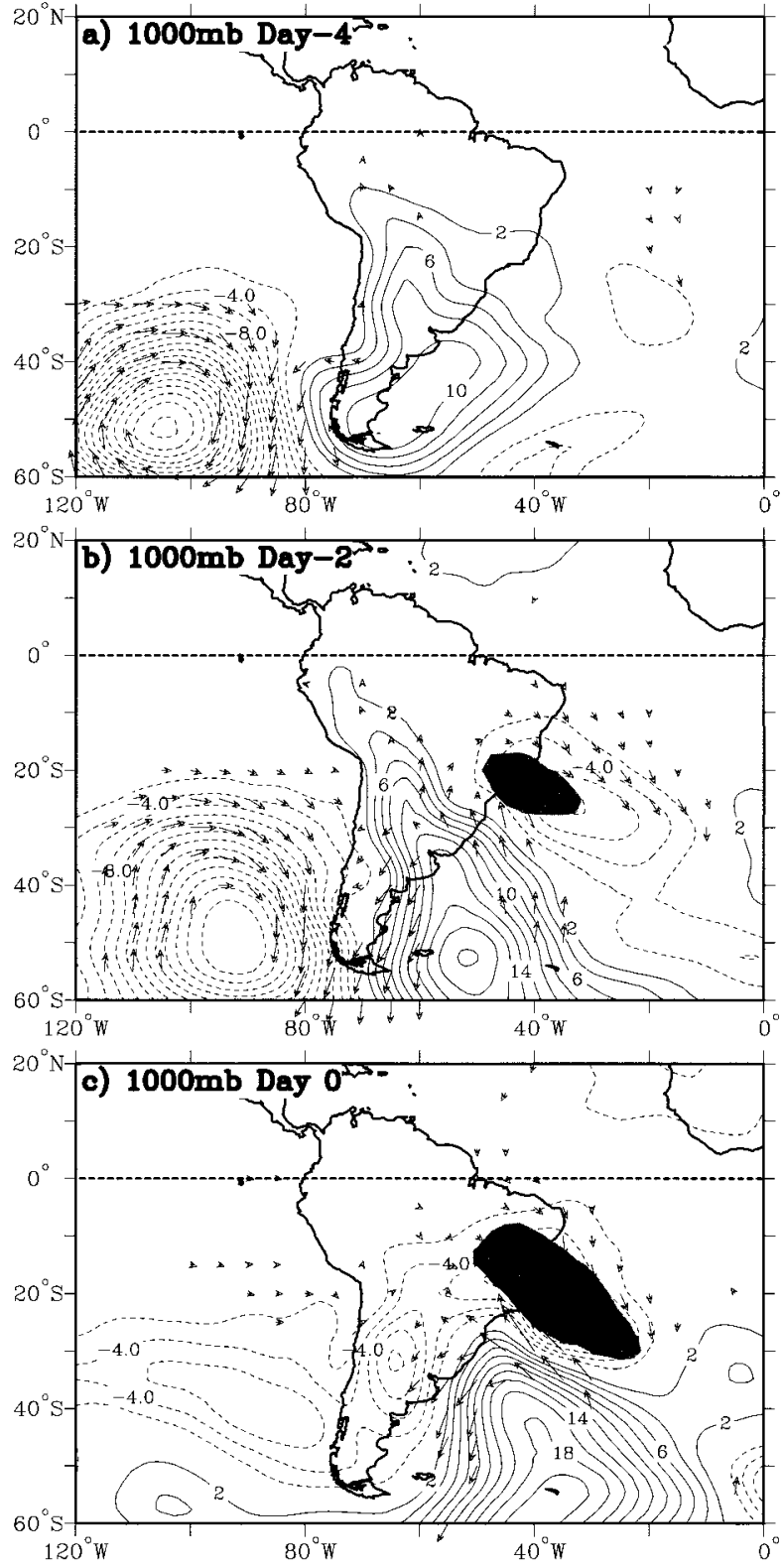

FIG. 8. As in Fig. 4 except field is 1000 -mb geopotential for (a) field leading base by 4 days, (b) field leading base by 2 days, and (c) field is simultaneous with base. Contour interval is $1 \mathrm{~m}$.

negative temperature anomalies have increased in amplitude and remain southwest of the OLR anomaly within the region of anomalous southeasterly advection in Fig. 8c. From the winds shown in Fig. 8, this air mass is seen to be associated with cold air advection from the South Atlantic. There is only a slight positive temperature perturbation in the anomalous northwesterly flow within the SACZ convective activity, consistent with the weak temperature gradients over tropical South America at this time of year.

The evolution shown in the preceding figures is consistent with a wave train propagating into the region of 

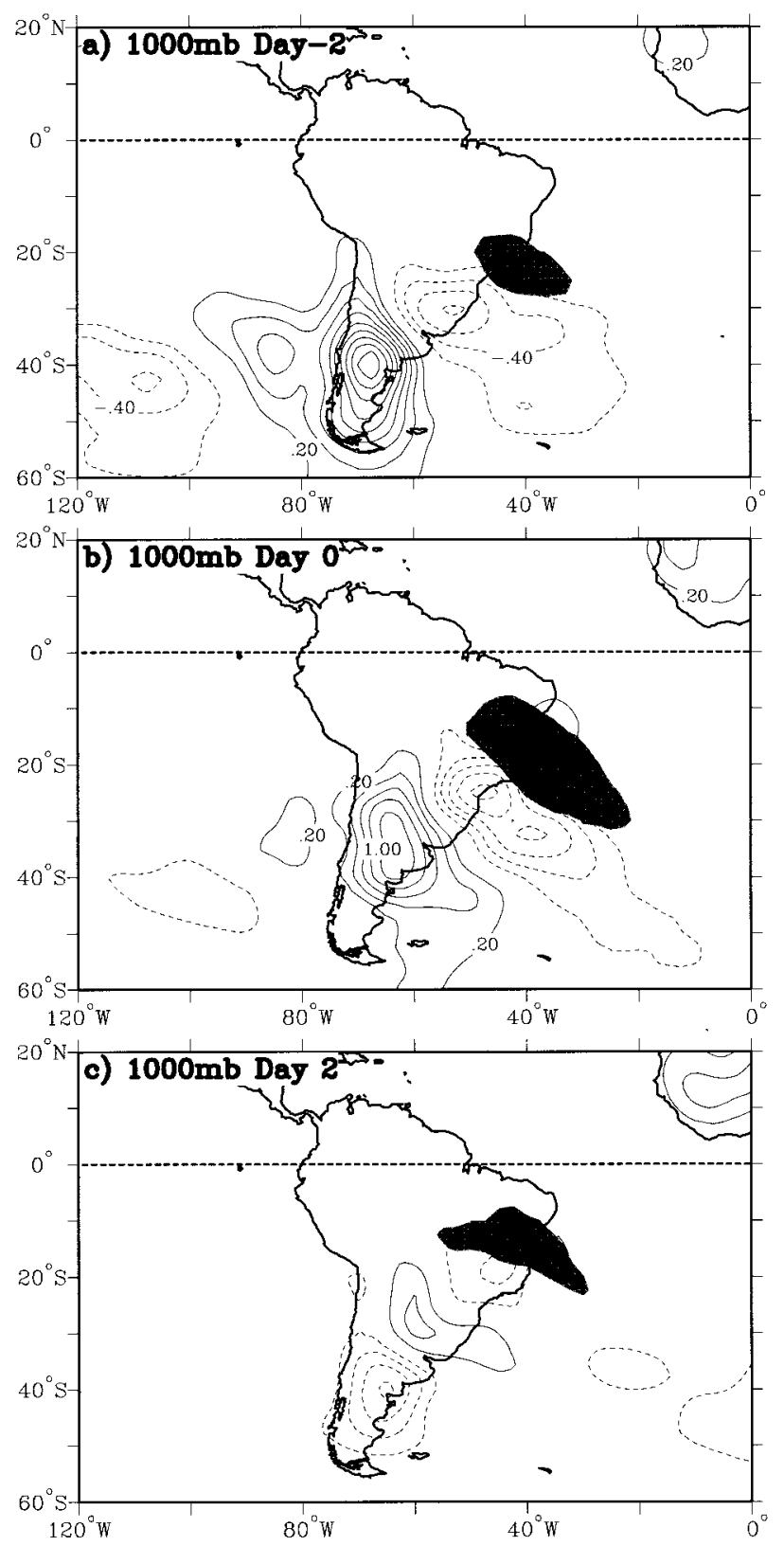

FIG. 9. As in Fig. 4 except field is 1000-mb temperature. Contour interval is $0.2^{\circ} \mathrm{C}$, with zero contour omitted.

the SACZ, where baroclinic development along an associated cold front occurs (Kousky 1979). Uplift is likely provided by a combination of a cold front and vorticity advection at upper levels. The wind vectors at 850 $\mathrm{mb}$ indicate that moisture for the convection in the vicinity of the SACZ originates in the Amazon Basin. This result seems to be roughly consistent with the composite moisture flux vectors obtained by Nogués-Paegle and Mo (1997) for periods of active convection in the SACZ, although their results show a contribution from the equatorial Atlantic as well. While some fraction of OLR variance within the SACZ is left unexplained by the fields we have shown, the results suggest that the most systematic variations in convection result from wave activity forcing from midlatitudes.

\section{2) AMAZON BAsin}

It is interesting to contrast circulation anomalies related to SACZ convection with those related to convection over the Amazon Basin at the same time of year. For this analysis we have chosen two OLR base regions, one over southwestern Amazonia $\left(5^{\circ}-15^{\circ} \mathrm{S}, 70^{\circ}-60^{\circ} \mathrm{W}\right)$ and the other over southeastern Amazonia $\left(5^{\circ}-15^{\circ} \mathrm{S}\right.$, $\left.60^{\circ}-50^{\circ} \mathrm{W}\right)$. Although rainfall in both these regions drains into the Amazon River, the point to the east is actually located over the Brazilian highlands. During southern summer, the heaviest convective rainfall over South America is farthest south in its seasonal migration and located over these regions, as seen in Fig. 1.

Figure 10 shows the evolution of $200-\mathrm{mb}$ streamfunction and the OLR center for convection over southwestern Amazonia. Over the 3-day sequence starting at day -2 , the OLR signal is seen to move rapidly northward into the base region from a location over Uruguay. Once again the upper-level streamfunction pattern shows a wave train propagating into southern South America, and although the OLR signal does seem to be associated with an upper-level trough, the evolution is quite different than in the analogous SACZ case. On day -2 and day -1 the OLR signal is located ahead of the upper trough, but by day 0 the trough continues to propagate zonally in midlatitudes and is essentially divorced from the negative OLR anomaly at low latitudes.

A reason for the lack of a strong upper-level relationship with Amazonian convection perhaps can be understood from Fig. 11, which shows the 1000-mb geopotential perturbation field and winds for the same sequence as in Fig. 10. The convection is collocated with a surface low pressure center over Uruguay on day -2 (Fig. 11a). This cyclone is located one-quarter wavelength ahead of the upper trough in Fig. 10a and is therefore indicative of a developing baroclinic wave. As the surface cyclone moves offshore in Figs. 11b and $11 \mathrm{c}$, however, a high pressure surge wraps around the southern Andes and moves rapidly equatorward along the eastern flank of the mountains. This surge appears to "push" the OLR signal into southwestern Amazonia by day 0 . This is an even stronger version of the pressure surge seen in Fig. 8 and is also associated with cold advection as in the previous case (not shown). Examination of this full temperature sequence (not shown) again reveals the appearance of a front, with low OLR anomalies appearing on the leading edge of the negative temperature perturbation. The convective signal grows as the cold air is advected northward, even though the magnitude of the temperature anomaly itself decreases as the air mass moves into the Tropics.

The events described here leading to convection over 

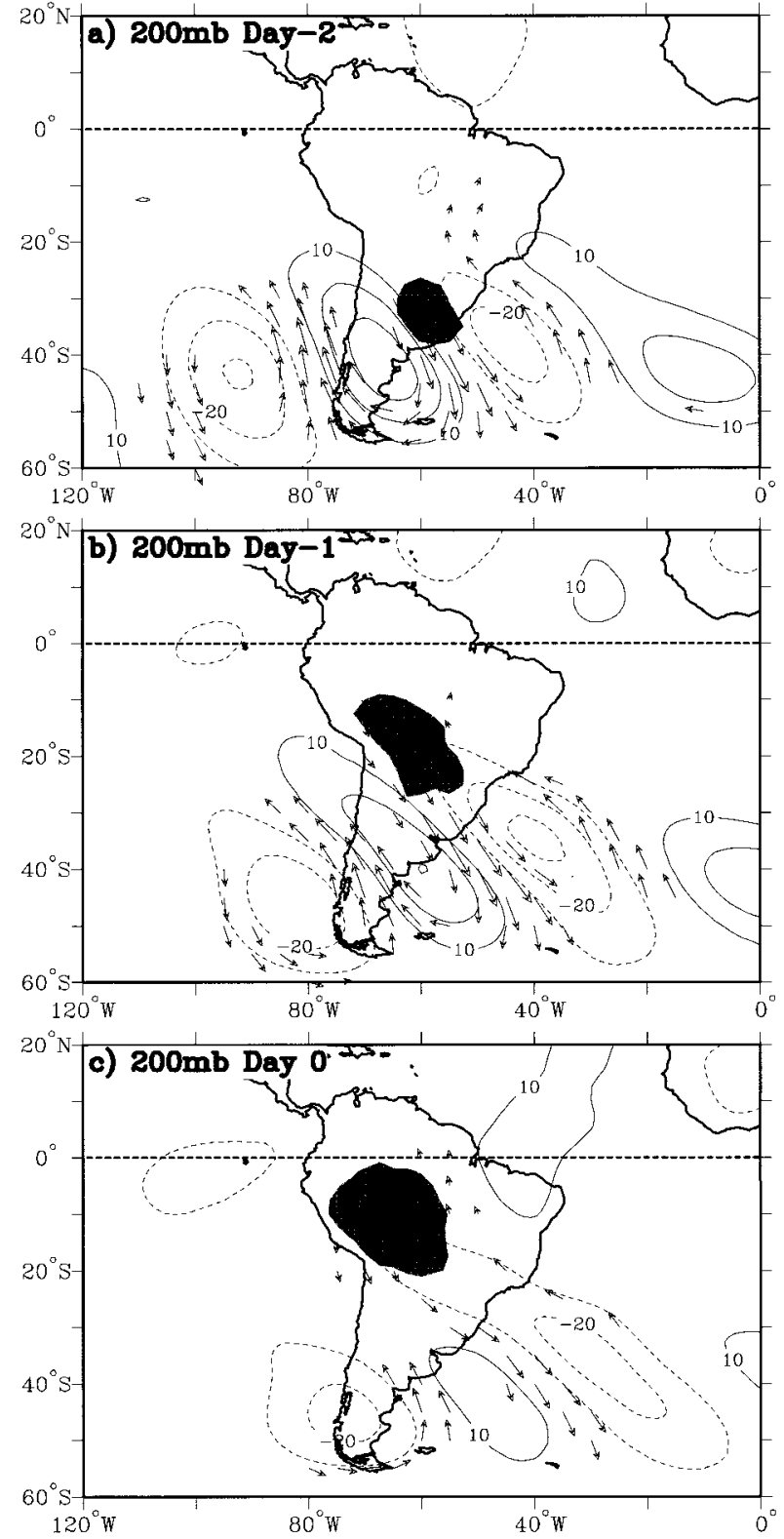

FIG. 10. As in Fig. 4 except base point is averaged from $5^{\circ}$ to $15^{\circ} \mathrm{S}$, $70^{\circ}$ to $60^{\circ} \mathrm{W}$ for (a) field leading base by 2 days, (b) field leading base by 1 day, and (c) field simultaneous with base.

southwestern Amazonia appear entirely consistent with the composite analysis of Garreaud and Wallace (1998), who documented cold air incursions along the lee of the Andes during summer, although their base point was located farther south and east. Their composites led them to propose the following scenario, which is consistent with that developed by Gan and Rao (1994), and with other studies of synoptic disturbances near northsouth topography. A midlatitude trough approaching from the west strengthens downslope, relatively warm westerlies to the east of the Andes. The "lee trough" induced by adiabatic warming causes northerly winds
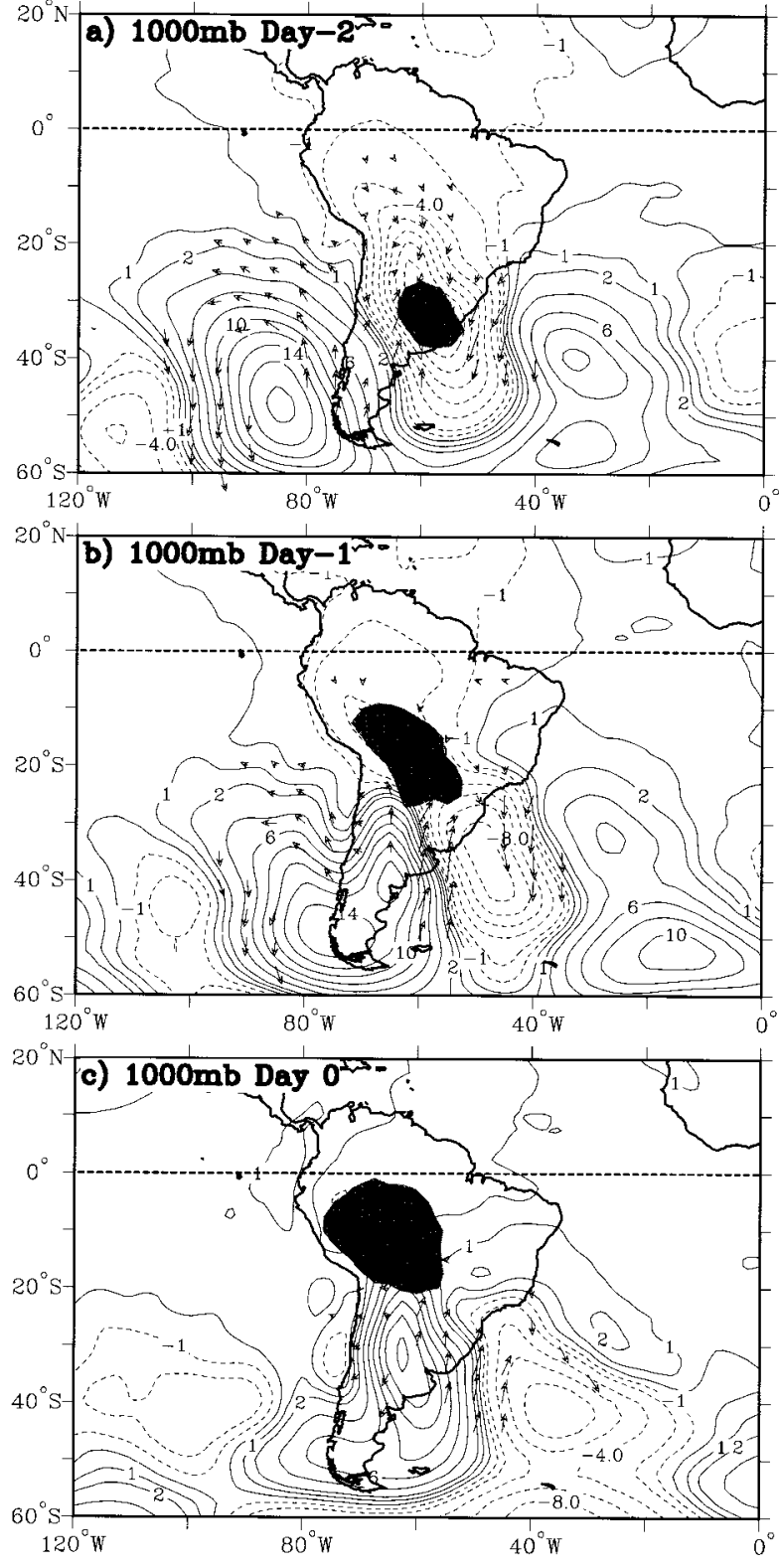

FIG. 11. As in Fig. 10 except that field is $1000-\mathrm{mb}$ geopotential and contours start at $1 \mathrm{~m}$.

that provide moist air from the Tropics. A few days later the surface high associated with the approaching upperlevel ridge displaces the low. Topographically confined ageostrophic winds now advect the high northward, along with cold air that triggers convection on its leading edge. The convection and low-level features become disconnected from the upper-level trough and ridge, which continue to move eastward.

The southeastern Amazon base region lies northwest of the SACZ base region and $10^{\circ}$ east of the southwestern Amazonian base region discussed above. The contour interval and OLR threshold for shading in these plots have been slightly reduced, owing to a weaker 

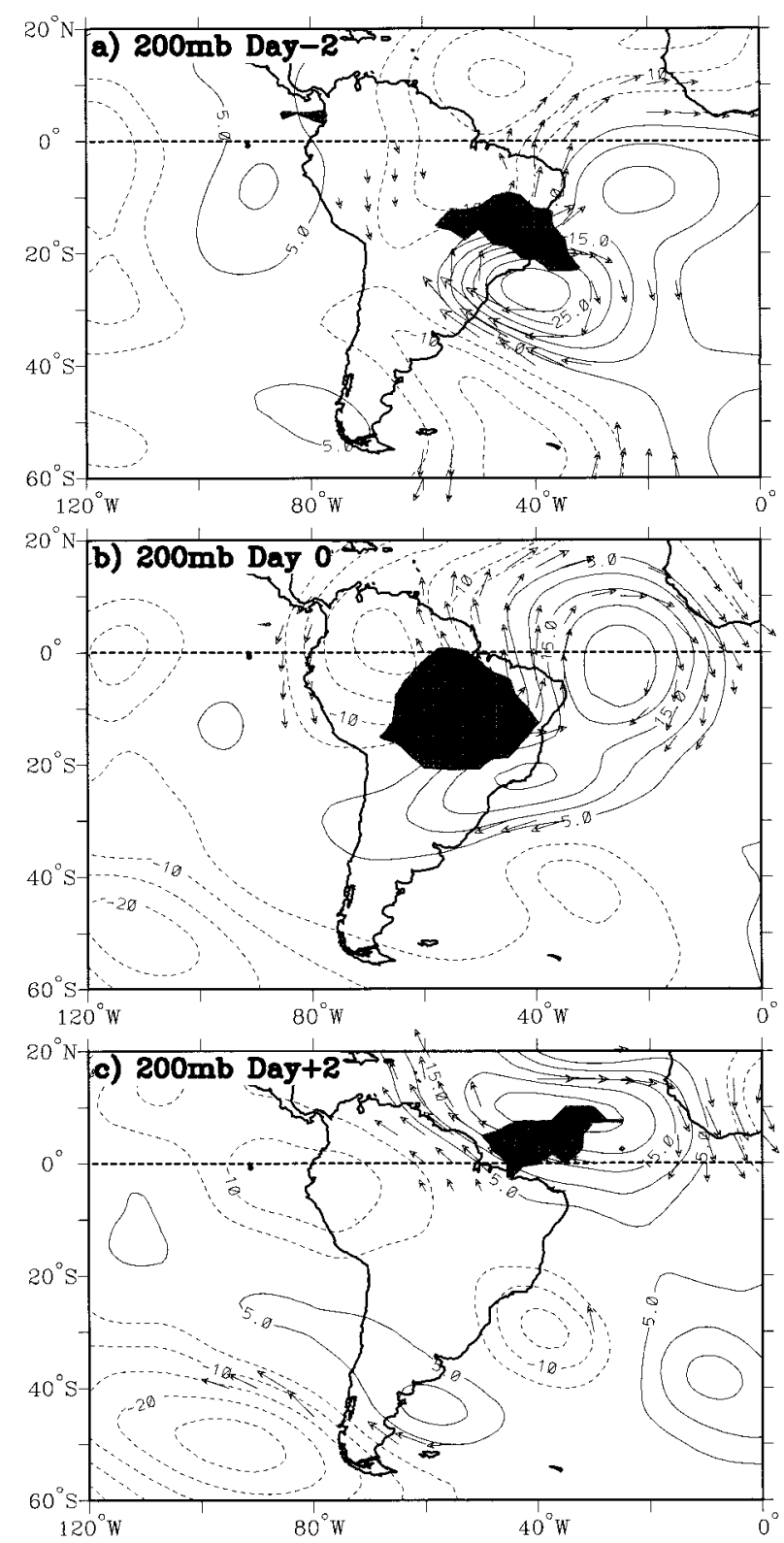

FIG. 12. As in Fig. 4 except base is average from $5^{\circ}$ to $15^{\circ} \mathrm{S}, 60^{\circ}$ to $50^{\circ} \mathrm{W}$, and contours are at an interval of $5 \times 10^{5} \mathrm{~m}^{2} \mathrm{~s}^{-1}$.

signal. In Fig. 12, the OLR and 200-mb circulation evolution from day -2 to day +2 are shown. As in the southwestern Amazonia and SACZ base regions, the OLR signal moves steadily northward through the period, with convection starting near the northern edge of the SACZ region on day -2 (Fig. 12a). The OLR and circulation perturbations at this stage in fact resemble the signature following the peak in SACZ convection (Fig. 4c), where convection is occurring in anomalous westerly flow on the equatorward side of an upper-level trough. The evolution prior to Fig. 12a, however, does not resemble the SACZ case (not shown), as the upper trough in Fig. 12a is not part of a wave train from the
Pacific, but moves northward into the region from the South Atlantic.

As the convection moves northward over southeastern Amazonia (Fig. 12b), a large region of outflow across the equator into the North Atlantic forms between two opposing circulations centered on the equator. This result is almost identical to that obtained by Kiladis and Weickmann (1997; their Fig. 6a) from a smaller observational sample using the same base region and season. It is also similar in many respects to the response calculated by Figueroa et al. (1995, their Fig. 14b) and Gandu and Geisler (1991, their Fig. 8) in their model simulations of transient heating at nearly the same location. In both these experiments the northward flow out of the heating region crossing the equator is especially prevalent. Some of the differences between the model and observations may be due in part to the fact that Gandu and Geisler used a motionless basic state and Figueroa et al. used a zonal mean basic state in their experiments. In general, Kiladis and Weickmann (1997) found robust signals of upper-level outflow into the winter hemisphere for convection occurring near the equator during solstitial seasons over most sectors of the globe.

As the convection continues to evolve, it moves rapidly northward, crossing the equator and enhancing the western portion of the Atlantic ITCZ (Fig. 12c). Most of the statistically relevant circulation is now in the Northern Hemisphere. Previously, Kiladis and Weickmann (1992b, 1997) have established that much of the Atlantic ITCZ convective variability during northern winter is related to equatorward-propagating wave activity originating over North America. The evolution in Fig. 12 is intriguing in that it suggests another, crossequatorial source of variability originating over Amazonia.

The lower-level signals for convection in southeastern Amazonia (not shown) do not show any evidence for pressure surges, as was seen to the west, nor do they have statistically significant temperature perturbations associated with them. At $850 \mathrm{mb}$, there is evidence of a large-scale, low-level "cyclone pair," located about the equator, propagating into the region from the Atlantic such that the convection occurs in anomalous westerlies as at $200 \mathrm{mb}$. The complicated structure of these events will be explored in the future. We can conclude here, however, that the bulk of the convection at this southeastern Amazonian location is not related to forcing from the extratropics of the Southern Hemisphere.

In summary, the signals associated with Amazon convection are in distinct contrast to the events that conspire to produce precipitation in the vicinity of the SACZ. The SACZ case seems to be an example of baroclinic development, with strong upper-level support in addition to a surface front associated with developing convection. Over southwestern Amazonia, convection also is associated with low-level cold air advected from the south, but it is less directly connected to the upper-level 

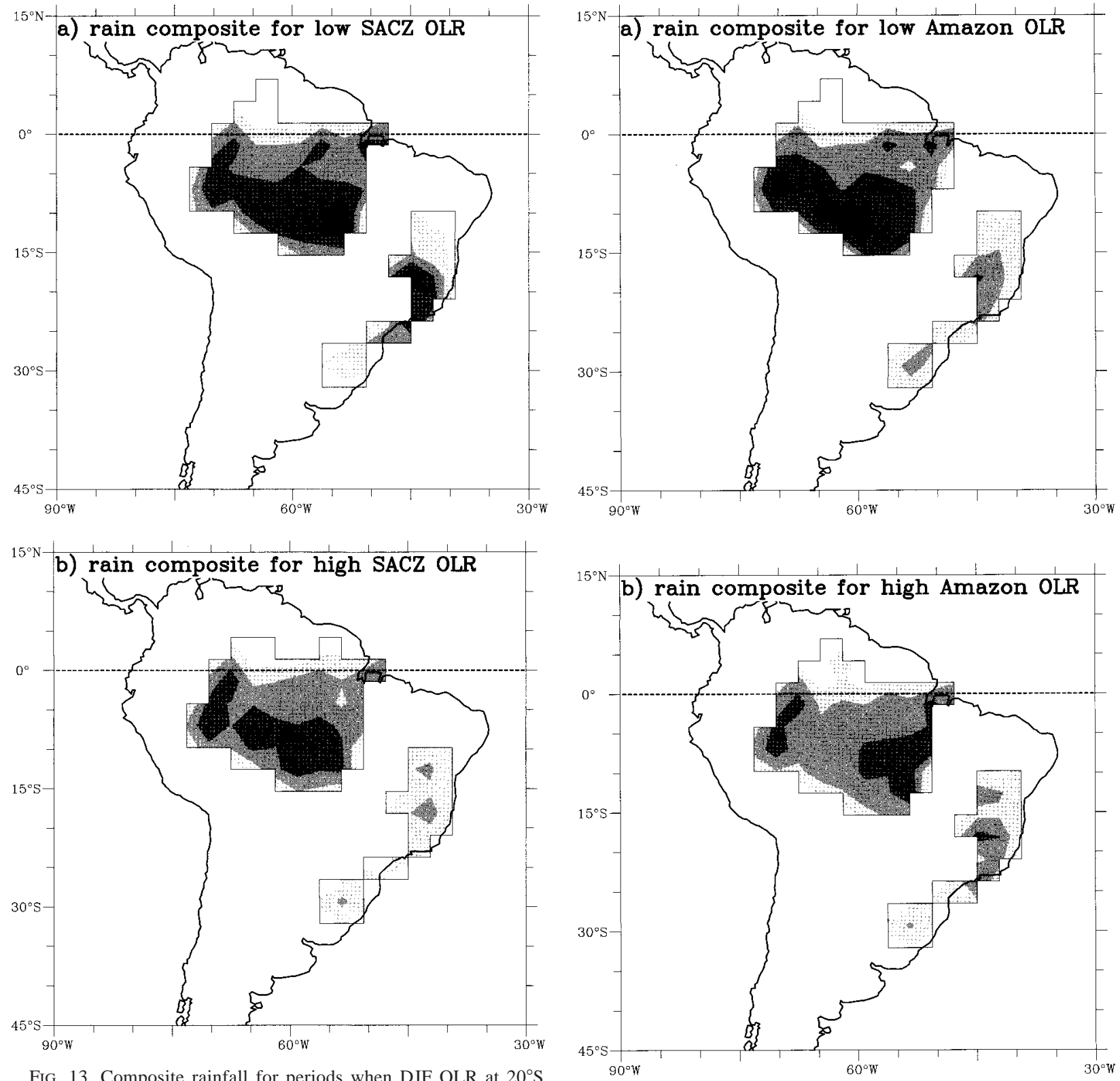

FIG. 13. Composite rainfall for periods when DJF OLR at $20^{\circ} \mathrm{S}$, $45^{\circ} \mathrm{W}$, filtered to include periods less than 30 days, is at least 1.5 standard deviations (a) below and (b) above mean. Data from stations within $2.5^{\circ}$ squares have been averaged. Shading starts at $3 \mathrm{~mm} \mathrm{day}^{-1}$ with an interval of $3 \mathrm{~mm} \mathrm{day}{ }^{-1}$. Thin lines depict regions where data are available.

wave activity. Over southeastern Amazonia, although convection appears to move into the region from the south, there is no evidence of wave train propagation from the south and little signature in temperature.

\section{c. Composites of rainfall}

To show that high-pass filtered OLR anomalies that we have been using as an independent variable do indeed reflect variations in rainfall, we composite rainfall

FIG. 14. As in Fig. 13 except that OLR is centered at $10^{\circ} \mathrm{S}, 65^{\circ} \mathrm{W}$.

from both the SACZ and in the Amazon Basin, based on periods when 2-30-day OLR anomalies exceed 1.5 standard deviations. Unfortunately, spatial coverage is incomplete. When OLR at $20^{\circ} \mathrm{S}, 45^{\circ} \mathrm{W}$ is anomalously low (Fig. 13a), rainfall in the southeast Amazon and in southeast Brazil exceeds $12 \mathrm{~mm}$ day $^{-1}$. On the other hand, for high OLR anomalies (Fig. 13b), rainfall in southeast Brazil averages less than $9 \mathrm{~mm}$ day $^{-1}$.

Over the Amazon basin, composites of rainfall based on low and high values of filtered OLR also show large differences. For low OLR at $10^{\circ} \mathrm{S}, 65^{\circ} \mathrm{W}$ (Fig. 14a), rainfall in the southern Amazon near the base point exceeds $12 \mathrm{~mm}$ day $^{-1}$, while for high OLR (Fig. 14b), 
there is less than $9 \mathrm{~mm} \mathrm{day}{ }^{-1}$ in most locations. The differences over southeast Brazil are small.

\section{Discussion}

Although the results of this and of many previous studies show that intraseasonal convection in the SACZ is at least partly related to forcing by midlatitudes, they do not reveal why the time mean SACZ should be found in its observed location. It is likely that Amazon convection plays some role, as all the world's subtropical convergence zones emanate from a region of deep tropical convection (Kodama 1992, 1993). Furthermore, Lenters and Cook (1995) found a realistic SACZ in a GCM that included continentality (with time mean convection), but no orography or longitudinal sea surface temperature gradients (although their inclusion improves the comparison with observations).

While we find no evidence of a systematic relationship between convection in the central Amazon and that in the SACZ on submonthly timescales, many modeling studies have indicated that there should be such a relation. For example, the study of Figueroa et al. (1995) showed that it is possible to produce mean low-level convergence in the vicinity of the SACZ, given diurnal convection in the Amazon. Although the initial response to Amazon heating was shown to produce an SACZlike structure in simple models (e.g., Silva Dias et al. 1983; Demaria 1985; Gandu and Geisler 1991), it was simulated only weakly in the steady-state response. Lenters and Cook (1995), however, found a realistic SACZ in a GCM with steady Amazon heating.

An indirect, although equally important, role of Amazon convection may be through its influence on the basic state. The preferred path of equatorward Rossby wave propagation over South America is related to the large-scale basic state, such that wave energy is refracted northward preferentially to the east of the Andes (Ambrizzi and Hoskins 1997). This basic state is ultimately generated by large-scale sources and sinks of diabatic heating, such as Amazon convection, altered by the presence of the Andes and Antarctica. Consistent with this scenario, Lenters and Cook (1995) found that significant moisture flux into the region of the SACZ in their GCM simulation resulted from transient activity.

In a study of the eastern tropical Pacific during northern winter, Kiladis and Weickmann (1992b) established that Rossby wave energy originating in the extratropics was the primary mechanism responsible for triggering ITCZ convection to the east of the dateline. The evolution was similar to that shown here for the SACZ, whereby convection was maximized ahead of upperlevel troughs in regions of positive vorticity advection. Kiladis (1998) further utilized $\mathbf{E}$ vector diagnostics (Hoskins et al. 1983) to show that the eastern Pacific was a preferred region of equatorward Rossby wave propagation.

The climatological DJF 2-30-day E vector field at

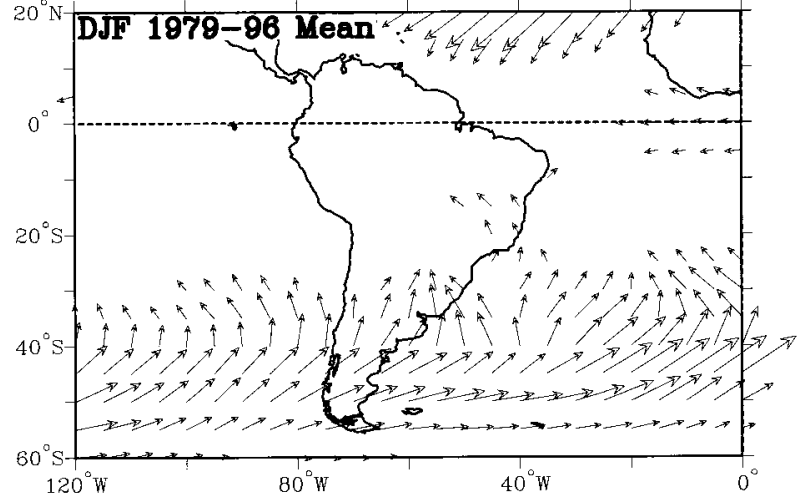

FIG. 15. Climatological 200-mb 2-30-day E vectors for DJF. The largest vectors are around $100 \mathrm{~m}^{2} \mathrm{~s}^{-2}$, and vectors less than $15 \mathrm{~m}^{2} \mathrm{~s}^{-2}$ are not shown.

$200 \mathrm{mb}$ over the South American sector is shown in Fig. 15. Detailed explanations of the $\mathbf{E}$ vector itself are given by Hoskins et al. (1983) and Kiladis (1998). If certain assumptions are satisfied, the vector approximates the preferred direction of the group velocity of Rossby waves. The figure shows that equatorward propagating Rossby wave dispersion is prevalent along the main southern storm track between $40^{\circ}$ and $50^{\circ} \mathrm{S}$ throughout the entire sector, as represented by the relatively large amplitude $\mathbf{E}$ vectors directed northward to the east of the Andes. The region where the $\mathbf{E}$ vectors extend farthest into the Tropics is at the longitude of the SACZ, in line with the preferred wave guide shown by Ambrizzi and Hoskins (1997) and the tilted wave activity propagating equatorward shown in the present study. Thus the preference for wave activity to propagate into low latitudes in the vicinity of the SACZ appears to be a major factor in determining the location and quasi-periodicity of SACZ convection.

Another possibility is that the location of the SACZ is determined by the availability of moisture. For example, if a low-level cyclone forms too far south or west, it will not be able to tap the moisture of the Amazon basin. Thus, even with a random assortment of waves impinging on the region, only those with a certain phasing would result in the advection of moisture from the Amazon. It is important to realize, as we have shown, that the supply of moisture is not dependent on the occurrence of Amazonian convection, but only on the availability of low-level moisture from that region.

This interpretation is consistent with the moisture flux composites of Nogués-Paegle and Mo (1997). When the SACZ is well developed (their Figs. $4 \mathrm{c}$ and $4 \mathrm{~d}$ ), both the Amazon Basin and the tropical Atlantic provide moisture (their Figs. 8a and 8b). When the SACZ is weak (their Figs. $4 \mathrm{a}$ and $4 \mathrm{~b}$ ) and convection is now developed farther south (around $30^{\circ} \mathrm{S}$ ), moisture seems to be transported from Amazonia via an intense lowlevel jet. The position of low OLR is consistent with the maximum in variance we show in Fig. 3a and with 
a preferred location of MCCs over South America during summer (e.g., Velasco and Fritsch 1987).

We show that when convection is developed in the preferred MCC region (outside the SACZ), a low-level low is developed near $30^{\circ} \mathrm{S}$ (Fig. 11a). We argue that when a low is developed south of $30^{\circ} \mathrm{S}$, less moisture from the Amazon Basin is available and convection does not develop. The corresponding map at $850 \mathrm{mb}$ (not shown) reveals northerly winds consistent with the low and with a low-level jet.

\section{Summary}

Using lead and lag regressions of circulation, temperature, pressure, and OLR onto variations of OLR, we have shown evidence that submonthly variations in the cloudiness field that defines the SACZ are influenced by wavelike features propagating into the region from the extratropics. Although some portion of convective variability within the SACZ is still unexplained by the regression results shown here, the signal isolated by this technique, much like a composite approach, will reveal the most "preferred" pattern of circulation associated with episodes of anomalously low OLR within the SACZ.

The signal associated with SACZ convection appears to be that of a Rossby wave originating within the midlatitude westerly belt of the Southern Hemisphere. This is consistent with other studies that have linked variations in the SPCZ to those in the SACZ (e.g., Kalnay et al. 1986; Grimm and Silva Dias 1995; Nogués-Paegle and Mo 1997; Lenters and Cook 1998). The vertical structure of the wave trains is nearly equivalent barotropic over the ocean, as is typically observed in the Southern Hemisphere (e.g., Kidson 1991) The wave energy propagates along a great-circle route, toward southern South America, and then northward as a baroclinic disturbance develops upon reaching the vicinity of the SACZ.

We contrast this development with cold air outbreaks that propagate equatorward to the lee of the Andes as low-level pressure surges, which are linked to convection over southwestern Amazonia. For a description of the latter phenomenon see papers by Gan and Rao (1994) and Garreaud and Wallace (1998). Over southeast Amazonia, convection does not appear to be linked to extratropical forcing, but instead is preceded by disturbances propagating westward into the region from the tropical Atlantic. This convection results in strong upper-level outflow into the Northern Hemisphere.

It is not clear what determines the preferred position of the SACZ. A purely wave-driven phenomenon should have a more-or-less random phase. We believe that the observed position is partly due to the preferred path of Rossby wave energy dispersing equatorward by the wave guiding of the basic state (Ambrizzi and Hoskins 1997). In turn, the basic state is maintained by deep Amazon convection among many other factors. Forcing from the Amazon may also contribute more directly to positioning the SACZ by producing a region of lowlevel convergence (e.g., Lenters and Cook 1995; Figueroa et al. 1995). These influences, combined with the ability of northwesterly flow ahead of propagating troughs to efficiently tap moisture from the Amazon Basin, result in the preferred position of the SACZ, although this will certainly vary from case to case depending on the details of the wave train and perhaps moisture availability at any given time. It would be of interest to examine interannual variability in the SACZ to establish the extent that the cloud band is dependent on the presence of the wave activity, as is the case in the eastern tropical Pacific (Kiladis 1998).

Acknowledgments. We wish to thank M. A. Silva Dias, P. Silva Dias, P. Satyamurty, Julia Nogués-Paegle, M. Kayano, and both anonymous reviewers for useful discussions and/or comments. Rainfall data were generously provided by the Brazilian National Agency for Electric Energy. Funding from the Inter-American Institute for Global Change Research and the Pan American Climate Studies Program of the NOAA Climate and Global Change Program made this study possible.

\section{REFERENCES}

Aceituno, P., 1988: On the functioning of the Southern Oscillation in the South American sector. Part I: Surface climate. Mon. Wea. Rev., 116, 505-524.

Ambrizzi, T., and B. J. Hoskins, 1997: Stationary Rossby-wave propagation in a baroclinic atmosphere. Quart. J. Roy. Meteor. Soc., 123, 919-928.

Blackmon, M. L., Y.-H. Lee, and J. M. Wallace, 1984: Time variation of $500 \mathrm{mb}$ height fluctuations with long, intermediate and short time scales as deduced from lag-correlation statistics. J. Atmos. Sci., 41, 981-991.

Casarin, D. P., and V. E. Kousky, 1986: Anomalias de precipitaco no sul do Brasil e variacões na circulacoes atmosférica. Rev. Bras. Meteor., 1, 83-90.

DeMaria, M., 1985: Linear response of a stratified tropical atmosphere to convective forcing. J. Atmos. Sci., 42, 1944-1959.

Duchon, C. E., 1979: Lanczos filtering in one and two dimensions. J. Appl. Meteor., 18, 1016-1022.

Figueroa, S., P. Satyamurti, and P. L. Silva Dias, 1995: Simulation of the summer circulation over the South American region with an Eta coordinate model. J. Atmos. Sci., 52, 1573-1584.

Gan, M. A., and V. Rao, 1991: Surface cyclogenesis over South America. Mon. Wea. Rev., 119, 1293-1302.

— , and — 1994: The influence of the Andes cordillera on transient disturbances. Mon. Wea. Rev., 122, 1141-1157.

Gandu, A. W., and J. E. Geisler, 1991: A primitive equations model study of the effect of topography on the summer circulation over tropical South America. J. Atmos. Sci., 48, 1822-1836.

Garreaud, R. D., and J. M. Wallace, 1998: Summertime incursions of midlatitude air into subtropical and tropical South America. Mon. Wea. Rev., 126, 2713-2733.

Grimm, A. M., and P. L. Silva Dias, 1995: Analysis of tropicalextratropical interactions with influence functions of a barotropic model. J. Atmos. Sci., 52, 3538-3555.

Hastenrath, S., 1991: Climate Dynamics of the Tropics. Kluwer, 486 pp.

Horel, J., A. Hahmann, and J. Geisler, 1989: An investigation of the annual cycle of the convective activity over the tropical Americas. J. Climate, 2, 1388-1403. 
Hoskins, B. J., and T. Ambrizzi, 1993: Rossby wave propagation on a realistic longitudinally varying flow. J. Atmos. Sci., 50, 16611671.

- I. N. James, and G. H. White, 1983: The shape, propagation and mean-flow interaction of large-scale weather systems. $J$. Atmos. Sci., 40, 1595-1612.

Hsu, H.-H., 1987: Propagation of low-level circulation features in the vicinity of mountain ranges. Mon. Wea. Rev., 115, 1864-1892.

Kalnay, E, K. C. Mo, and J. Paegle, 1986: Large-amplitude, shortscale stationary Rossby Waves in the Southern Hemisphere: Observations and mechanistic experiments to determine their origin. J. Atmos. Sci., 43, 252-275.

— project. Bull. Amer. Meteor. Soc., 77, 437-471.

Kidson, J. W., 1991: Intraseasonal variations in the Southern Hemisphere circulation. J. Climate, 4, 939-953.

- and M. R. Sinclair, 1995: The influence of persistent anomalies on Southern Hemisphere storm tracks. J. Climate, 8, 1938-1950.

Kiladis, G. N., 1998: Observations of Rossby waves linked to convection over the eastern tropical Pacific. J. Atmos. Sci., 55, 321355.

— , and K. M. Weickmann, 1992a: Circulation anomalies associated with tropical convection during northern winter. Mon. Wea. Rev. 120, 1900-1923.

, and - 1992b: Extratropical forcing of tropical Pacific convection during northern winter. Mon. Wea. Rev., 120, 19241938

_ and -1997 : Horizontal structure and seasonality of largescale circulations associated with submonthly tropical convection. Mon. Wea. Rev., 125, 1997-2013.

Kodama, Y.-M., 1992: Large-scale common features of subtropical precipitation zones (the Baiu frontal zone, the SPCZ, and the SACZ), Part I: Characteristics of subtropical frontal zones. $J$. Meteor. Soc. Japan, 70, 813-835.

_ 1993: Large-scale common features of sub-tropical convergence zones (the Baiu frontal zone, the SPCZ, and the SACZ), Part II: Conditions of the circulations for generating the STCZs. J. Meteor. Soc. Japan, 71, 581-610.
Kousky, V. E., 1979: Frontal influences on Northeast Brazil. Mon. Wea. Rev., 107, 1140-1153.

Lenters, J. D., and K. H. Cook, 1995: Simulation and diagnosis of the regional summertime precipitation climatology of South America. J. Climate, 8, 2988-3005.

- , and - 1998: Summertime precipitation variability over South America: Role of the large-scale circulation. Mon. Wea. Rev., 127, 409-431.

Liebmann, B., and D. L. Hartmann, 1984: An observational study of tropical-midlatitude interaction on intraseasonal timescales during winter. J. Atmos. Sci., 41, 3333-3350.

_, and C. A. Smith, 1996: Description of a complete (interpolated) outgoing longwave radiation dataset. Bull. Amer. Meteor. Soc., 77, $1275-1277$.

Livezey, R. E., and W. Y. Chen, 1983: Statistical field significance and its determination by Monte Carlo techniques. Mon. Wea. Rev., 111, 46-59.

Madden, R., and P. Julian, 1994: Observations of the 40-50-day tropical oscillation-A review. Mon. Wea. Rev., 122, 814-837.

Mohr, K. I., and E. J. Zipser, 1996: Mesoscale convective systems defined by their $85-\mathrm{GHz}$ ice scattering signature: Size and intensity comparison over tropical oceans and continents. Mon. Wea. Rev., 124, 2417-2437.

Nogués-Paegle, J., and K. C. Mo, 1997: Alternating wet and dry conditions over South America during summer. Mon. Wea. Rev., 125, 279-291.

Paegle, J., 1987: Interactions between convective and large-scale motions over Amazonia. The Geophysiology of Amazonia, R. Dickinson, Ed., John Wiley and Sons, 347-387.

Rao, V. B., and K. Hada, 1990: Characteristics of rainfall over Brazil: Annual variations and connections with the Southern Oscillation. Theor. Appl. Climatol., 42, 81-91.

Silva Dias, P. L., W. H. Schubert, and M. DeMaria, 1983: Large-scale response of the tropical atmosphere to transient convection. $J$. Atmos. Sci., 40, 2689-2707.

Velasco, I., and J. M. Fritsch, 1987: Mesoscale Convective Complexes in the Americas. J. Geophys. Res., 92(D8), 9591-9613.

Virji, H., 1981: A preliminary study of summertime tropospheric circulation patterns over South America estimated from cloud winds. Mon. Wea. Rev., 109, 596-610. 